\title{
Comparative Genomics Analysis Provides New Strategies for Bacteriostatic Ability of Bacillus velezensis HAB-2
}

\section{Peidong $\mathrm{Xu}^{1,2 t}$, Shangqian Xie ${ }^{1,3 t}$, Wenbo Liu't, Pengfei Jin' ${ }^{1}$, Dandan Wei ${ }^{1}$, Dahar Ghulam Yaseen', Yu Wang ${ }^{1}$ and Weiguo Miao ${ }^{1 *}$}

\begin{abstract}
1 Key Laboratory of Green Prevention and Control of Tropical Plant Diseases and Pests, Ministry of Education, College of Plant Protection, Hainan University, Haikou, China, ${ }^{2}$ School of Life and Pharmaceutical Sciences, Hainan University, Haikou, China, ${ }^{3}$ College of Forestry, Hainan University, Haikou, China
\end{abstract}

OPEN ACCESS

Edited by:

Yoshio Yamaoka,

Oita University, Japan

Reviewed by:

Manoj Kumar Solanki,

Agricultural Research Organization

(ARO), Israe

Ivica Z. Dimkiæ,

University of Belgrade, Serbia

*Correspondence:

Weiguo Miao

miao@hainu.edu.cn

tThese authors have contributed equally to this work

Specialty section:

This article was submitted to Evolutionary and Genomic

Microbiology,

a section of the journal

Frontiers in Microbiology

Received: 12 August 2020 Accepted: 29 October 2020 Published: 17 November 2020

Citation:

Xu P, Xie S, Liu W, Jin P, Wei D, Yaseen DG, Wang $Y$ and Miao $W$

(2020) Comparative Genomics Analysis Provides New Strategies for Bacteriostatic Ability of Bacillus

velezensis HAB-2.

Front. Microbiol. 11:594079. doi: 10.3389/fmicb.2020.594079
Biocontrol formulations prepared from biocontrol bacteria are increasingly applied in sustainable agriculture. Notably, inoculants prepared from Bacillus strains have been proven efficient and environmentally friendly alternatives to chemical bactericides. The bacterium Bacillus velezensis HAB-2 (formerly classified as $B$. amyloliquefaciens HAB-2) is used as a biological control agent in agricultural fields. In this study, we reported a high-quality genome sequence of HAB-2 using third-generation sequencing technology (PacBio RS II). The $3.89 \mathrm{Mb}$ genome encoded 3,820 predicted genes. Comparative analysis among the genome sequences of reference strains $B$. velezensis FZB42, B. amyloliquefaciens DSM7 and B. subtilis 168 with the HAB-2 genome revealed obvious differences in the variable part of the genomes, while the core genome shared by FZB42 and HAB-2 was similar (96.14\%). However, there were differences in the prophage region among the four strains. The numbers of prophage regions and coding genes in HAB-2 and FZB42 were smaller than the other two strains. The HAB-2 genome showed superior ability to produce secondary metabolites and harbored 13 gene clusters involved in synthesis of antifungal and antibacterial acting secondary metabolites. Furthermore, there were two unique clusters: one cluster which encoded lanthipeptide was involved in mersacidin synthesis and another cluster which encoded ladderane was shown to direct an unknown compound. Multidomain enzymes, such as non-ribosomal peptide synthetase and polyketide synthase, control the biosynthesis of secondary metabolites and rely on 4'-phosphopantetheinyl transferases (PPTases). Key genes IpaH2 and a encoded PPTases in HAB-2 encoded 224 and 120 amino acids, respectively. The genomic features revealed that HAB-2 possesses immense potential to synthesize antimicrobial acting secondary metabolites by regulating and controlling gene clusters. The prophage regions and genes encoding PPTases may provide novel insight for the bacteriostatic mechanism of Bacillus in the biological control of plant diseases. 


\section{INTRODUCTION}

Pathogenic microorganisms are a major and chronic threat to food production and ecosystem stability all over the world by infecting plant tissue and affecting plant health (Compant et al., 2005). As the human population has increased and agricultural production has intensified over the past few decades, producers have been increasingly dependent on agrochemicals to control plant diseases (Schäfer and Adams, 2015). However, excessive use of chemical pesticides has had a huge negative impact on the ecological environment. Increasingly, researchers and producers realize the need for alternatives to chemical pesticides to avoid damaging the environment. Use of beneficial bacteria as alternatives to chemical pesticides in plant protection is steadily increasing and is beginning to replace some chemical pesticides (Qiao et al., 2014). In China, according to the China Pesticide Information Network ${ }^{1}$, a total of 41,614 pesticide products were registered in China at the end of May 2020. Among them, 10,971 antiseptics accounted for $26.3 \%$. There were 434 actual microbial pesticides, and registered biological pesticides only accounted for $2.9 \%$ of the total pesticide products. Thus, prevention and control of plant diseases are still dominated by chemical pesticides in China, and the road to replace them with biological pesticides is long, but the development potential is huge. As a consequence, researchers are also focusing on the antibacterial mechanisms of biocontrol bacteria.

Bacillus velezensis is a biocontrol bacterium that is efficient, environmentally friendly and suitable for wide use for plant protection in agriculture. It produces natural products that are antimicrobial, antiviral and nematocidal (Mariappan et al., 2012). Recently, whole-genome assemblies of Bacillus spp. have been produced using high-throughput sequencing, and genome analysis of $B$. velezensis reveals their potential for biocontrol of plant pathogens (Chen et al., 2008). The B. velezensis genome harbors some important gene clusters involved in the synthesis of secondary metabolites. The cluster of protective molecules is generally made by non-ribosomal peptide synthetase (NRPS) and polyketide synthase (PKS) (Schneider et al., 2007; Chen et al., 2008; Beld et al., 2014). Five gene clusters (srf, bmy, fen, nrs, and $d h b$ ) were shown to direct synthesis of surfactin, fengycin and iturin (including bacillomycinD and mycosubtilin). Three gene clusters, $m \ln (p k s 1)$, bae(pks2), and $d f n(p k s 3)$, were shown to direct synthesis of the polyketides macrolactin, bacillaene and difficidin, respectively (Koumoutsi et al., 2004). The size of these gene clusters generally accounts for $7.5-8.5 \%$ of the genome of the strain (Koumoutsi et al., 2004; Chen et al., 2008).

In B. velezensis, NRPS and PKS control the biosynthesis of secondary metabolites (Metz et al., 2001; Cox, 2007). However, these enzymes are inactive until they are post-translationally modified. The activation of apo-peptidyl carrier proteins of NRPS and apo-acyl carrier proteins of PKS to their active holo form is accomplished by dedicated $4^{\prime}$-phosphopantetheinyl transferases (PPTases) (Lambalot et al., 1996). The synthesis of non-ribosomal lipopeptides and polyketides are dependent on the PPTases, which are encoded by a functional sfp gene (Chen et al., 2008).

${ }^{1}$ http://www.chinapesticide.org.cn/
A PPTase sfp was first identified by Nakano et al. (1990, 1992) in attempts to transform the non-surfactin-producing strain B. subtilis JH642. Borchert et al. (1994) identified a gene, gsp, with $34 \%$ identity and $54 \%$ homology to sfp. Huang et al. (1993) discovered $l p a-14$, showing homology to $s f p$, which is related to iturin A. Because of their cornerstone role in metabolism, PPTases are considered antibiotic targets in agriculture. Being indispensable for the biosynthesis of natural products with antibiotic action, the PPTase super family genes play a leading role in antibiotic engineering efforts for agriculture.

The bacterium $B$. velezensis $\mathrm{HAB}-2$ has the potential as a biological pesticide due to its excellent antibacterial ability. Our previous study provided evidence that HAB-2 was evaluated against 17 plant pathogens such as Colletotrichum gloeosporioides, Alternaria solani, and Fusarium oxysporum. The inhibition rates were ranged from $42.99-69.76 \%$. Furthermore, the strain could effectively inhibit the infection of C. gloeosporioides on the mango leaf and fruits, Alternaria solani on the tomato fruits, and prevent and control Oidium heveae (Jin et al., 2018). Analysis of the whole genome of $B$. velezensis will allow uncovering the antibacterial mechanism of biocontrol bacteria. In this study, we assembled the whole genome of $B$. velezensis $\mathrm{HAB}-2$, which not only showed a similar ability to produce antimicrobial secondary metabolites as for most Bacillus spp., but also demonstrated some unique abilities in our previous study (Jin et al., 2017). Furthermore, the assembled genome of HAB-2 was compared with the genomes of B. velezensis FZB42, B. amyloliquefaciens DSM7, and B. subtilis 168; genome annotation and comparative genomics analysis showed some important features including prophage regions, unique clusters, and key genes of these strains and also revealed that HAB-2 had great potential for biocontrol of plant pathogens.

\section{MATERIALS AND METHODS}

\section{Strain Culture and Type Genomes}

Bacillus velezensis HAB-2 was isolated from cotton (Gossypium hirsutum) root-soil in Xinjiang Province, China, and preserved in the Key Laboratory of Green Prevention and Control of Tropical Plant Diseases and Pests (Hainan University), Ministry of Education. The HAB-2 strain was cultivated in LuriaBertani agar medium and broth at $28^{\circ} \mathrm{C}$ with shaking at 180 $\mathrm{r} / \mathrm{min}$, and was used to extract genomic DNA. Type genome sequences of strains B. velezensis FZB42 (Chen et al., 2007, NC_009725.1), B. amyloliquefaciens DSM7 (Rückert et al., 2011, NC_014551.1) and B. subtilis 168 (Barbe et al., 2009, NC_000964.3) were collected from the National Center for Biotechnology Information (NCBI).

\section{Genomic DNA Extraction and Sequencing}

Genomic DNA from HAB-2 was extracted using commercial kits according to the instructions (Sigma Aldrich, St. Louis, MO, United States). The DNA quality was determined using Qubit and Nanodrop (both Thermo Fisher Scientific, Waltham, MA, United States). Then the qualified genomic DNA from B. velezensis HAB-2 was fragmented with G-tubes (Covaris, 
Woburn, MA, United States) and end-repaired to prepare SMRTbell DNA template libraries (with fragment size $>10 \mathrm{~kb}$ selected by bluepippin system) according to the specification (PacBio, Menlo Park, CA, United States). Library quality was detected by Qubit, and average fragment size was estimated on a Bioanalyzer 2100 (Agilent, Santa Clara, CA, United States). The SMRT sequencing was performed on a Pacific Biosciences RSII sequencer (PacBio, Menlo Park, CA, United States) according to standard protocols (MagBead Standard Seq v2 loading, $1 \times 180$ min movie) using P4-C2 chemistry.

\section{Genome Assembly}

Continuous long reads were generated from three SMRT sequencing runs. Reads $>500$ bp with a quality value $>0.75$ were merged into a single dataset. Next, the Hierarchical Genome Assembly Process (HGAP) pipeline (Chin et al., 2013) was used to correct for random errors in the long seed reads (seed length threshold $6 \mathrm{~kb}$ ). The resulting corrected and preassembled reads were used for de novo assembly using Celera Assembler with an overlap-layout-consensus strategy (Myers et al., 2000). Since SMRT sequencing features very little variation in quality throughout the reads (Koren et al., 2012), no quality values were used during the assembly. To validate the assembly quality and determine the final genome sequence, the Quiver consensus algorithm (Chin et al., 2013) was used to polish the assembly. Finally, the ends of the assembled sequence were trimmed to circularize the genome.

\section{Genomic Features Prediction and Annotations}

The open reading frame was predicted using GeneMarkS (Besemer et al., 2001). Repetitive elements were identified by RepeatMasker (Tarailo-Graovac and Chen, 2009). Noncoding RNA, such as rRNA, prediction was carried out using rRNAmmer (Lagesen et al., 2007), tRNAs were identified by tNRAscan (Lowe and Eddy, 1997) and compared with the Rfam database, and sRNAs were obtained using Infernal (Gardner et al., 2009). Several complementary approaches were utilized to annotate the assembled sequences. The genes were annotated by aligning with those deposited in diverse protein databases ( $E$-value $\leq 1 \mathrm{e}-5$, minimal alignment length percentage $\geq 40 \%$ ) including the NCBI non-redundant protein (Nr) database, UniProt/Swiss-Prot (UniProt Consortium, 2015), Kyoto Encyclopedia of Genesand Genomes (KEGG) (Kanehisa et al., 2016), Gene Ontology (GO) (Ashburner et al., 2000; Jones et al., 2014), Cluster of Orthologous Groups of proteins (COG) (Galperin et al., 2015; Makarova et al., 2015) and protein families (Pfam) (Finn et al., 2014). Additional annotation was carried out using the following databases: Pathogen Host Interactions (PHI) (Winnenburg et al., 2006), Virulence Factors of Pathogenic Bacteria (VFDB) (Chen et al., 2016), Antibiotic Resistance Genes Database (ARDB) (Liu and Pop, 2009), and Carbohydrate-Active enZYmes (CAZy) (Levasseur et al., 2013). Prophage was predicted using the PHAge SearchTool (PHAST ${ }^{2}$ ) as described by Zhou et al. (2011). Based on Nr annotation,

${ }^{2}$ http://phast.wishartlab.com/
GO annotation was carried out using Blast2GO (Conesa et al., 2005), and Pfam annotation was applied with PfamScan ${ }^{3}$ (Finn et al., 2014).

\section{Comparative Genomic Analysis}

In order to ensure the same annotation conditions, the genome data of the reference strains are analyzed based on the updated data in 2020 from NCBI, and the genome features are based on NCBI annotation. Genomics comparison of HAB2, FZB42, DSM7, and 168 was performed using MUMmer (Kurtz et al., 2004) and Mauve (version 2.3.1) (Darling et al., 2010). Gene families were constructed using genes of the reference and the target bacteria, and then the gene families were analyzed using the EDGAR software framework (Blom et al., 2009) to produce a Venn diagram. Phylogenetic analysis was performed to validate the phylogenetic relationship of HAB-2. The phylogenetic tree was constructed by the array of SNPs obtained from alignment of complete sample genomes against the reference. The phylogenetic tree drawn from the genomes of the four strains was constructed by TreeBeST (Nandi et al., 2010) using the method of PHYML (Wang D. et al., 2010) with bootstrap setting as 1,000. Based on $16 \mathrm{~S}$ rRNA sequences, the phylogenetic tree was constructed using the maximum likelihood method in MEGA7 software (Tamura et al., 2007) with bootstrap setting as 1,000. The secondary metabolite antibacterial gene clusters of the four strains were compared and analyzed using anti-SMASH 4.1.0 (Weber et al., 2015).

\section{RESULTS}

\section{Distinctive Genomic Features in the Prophage Region of Bacillus Strains}

The features of the genomes of Bacillus reference strains may differ due to the classification of the strains. Thus, we downloaded the genomes of the reference strains from the NCBI database and compared their genomic features with HAB-2. The summary features of the complete genome sequences of HAB-2, FZB42, DSM7 and 168 are summarized in Table 1 . There were 143,574 reads with a total of $1,350,725,830$ base pairs (bp) in HAB2 , and the sequencing data of $\mathrm{HAB}-2$ were de novo assembled

${ }^{3} \mathrm{ftp} / / / \mathrm{ftp}$. ebi.ac.uk/pub/databases/Pfam/Tools/PfamScan.tar.gz

TABLE 1 | Genomic feature comparisons among B. velezensis HAB-2, B. velezensis FZB42, B. amyloliquefaciens DSM7, and B. subtilis 168.

\begin{tabular}{lcccc}
\hline & HAB-2 & FZB42 & DSM7 & 168 \\
\hline Genome size (bp) & $3,894,648$ & $3,918,596$ & $3,980,199$ & $4,215,606$ \\
G + C content (mol\%) & 46.6 & 46.4 & 46.1 & 43.5 \\
Genes & 3,820 & 3,855 & 4,102 & 4,536 \\
Percent of coding region & 88.8 & 88.0 & 86.7 & 87.2 \\
Ribosomal RNA operons & 9 & 10 & 10 & 10 \\
Number of tRNAs & 86 & 89 & 94 & 86 \\
Phage-associated genes & 58 & 25 & 273 & 324
\end{tabular}




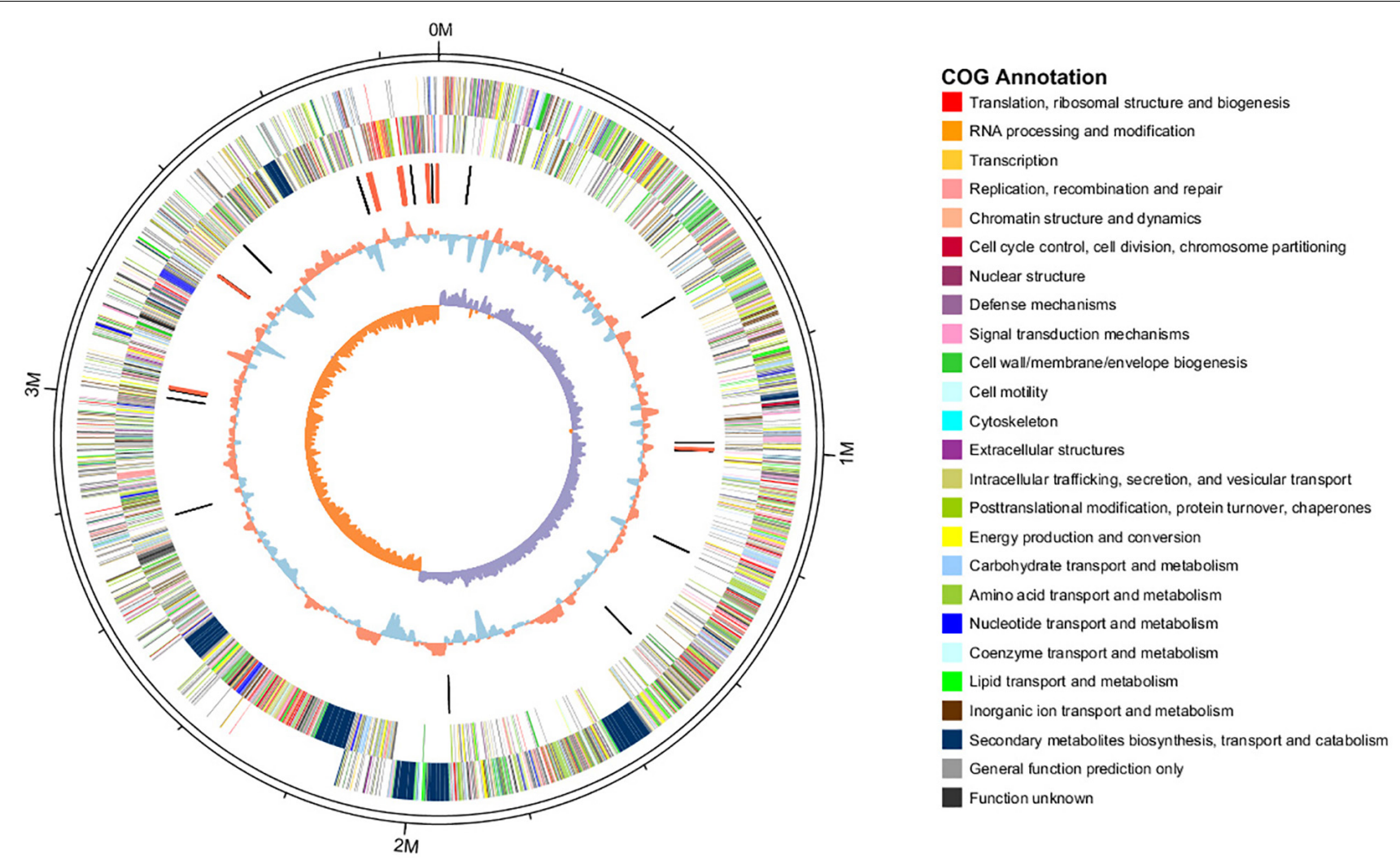

FIGURE 1 | Circular representation of B. velezensis HAB-2 genome. From outer to inner circle: first and second circles are positive and negative chain genes, respectively, all genes are color coded according to their COG annotation functions; third circle is ncRNA (black indicates tRNA and red indicates rRNA); fourth circle is $\mathrm{GC}$ content (red indicates greater than average value and blue indicates less than average); and fifth circle is $\mathrm{GC}$ skew $(\mathrm{GC}$ skew $=[(\mathrm{G}-\mathrm{C}) /(\mathrm{G}+\mathrm{C})$, purple indicates $>0$ and orange indicates $<0]$.

using HGAP. Genome circular representation can fully display the characteristics of the genome. We obtained a genome size of approximately $3,894,648 \mathrm{bp}$, consisting of a circular chromosome and leading to the one scaffold with N50 length of $3.89 \mathrm{Mb}$ and $46.64 \%$ GC content (Figure 1). The genome of HAB-2 was smaller than of $168(4,215,606 \mathrm{bp})$ and comparable to those of FZB42 $(3,918,596 \mathrm{bp})$ and DSM7 $(3,980,199 \mathrm{bp})$. A total of 3,820 genes were predicted, in which the maximum gene size was $16,302 \mathrm{bp}$ and the minimum was $114 \mathrm{bp}$. Furthermore, 86 tRNAs and nine sets of $16 s-23 s-5$ s ribosomal RNA operons were predicted in the genome (Table 1). The numbers of genes representing the core genome of strains HAB-2, FZB42, DSM7 and 168 were $3820,3855,4102$, and 4536, respectively (Table 1). The majority of the genes unique to DSM7 and 168 but not present in HAB-2 and FZB42 were phage related (Figure 2). Compared with FZB42, there was one more intact prophage region $[\operatorname{Pr} 2$, with 46 coding sequences (CDS)] in HAB-2 (Figure 2).

\section{Phylogenetic Analysis of $B$. velezensis HAB-2}

The classification of Bacillus strains has been constantly revised based on the development of molecular technology and the popularity of whole-genome sequencing, especially for B. velezensis. A phylogram based on Bacillus 16S rRNA, the most useful and is commonly used marker in the systematic classification of bacterium (Coenye and Vandamme, 2010) suggested a close relationship between the genomes of $B$. velezensis $\mathrm{HAB}-2$ and FZB42 (Figure 3A). To further clarify the relationships of $\mathrm{HAB}-2$ with the other relative species, the whole genomic SNPs was used to determine the evolutionary positions of the strains. The phylogenetic tree for HAB-2 and the reference strains was based on genomic scale SNPs (Figure 3B) and showed that HAB2 was most closely related to $B$. velezensis FZB42. Overall, evolutionary analysis showed that $\mathrm{HAB}-2$ was in the same branch with FZB42.

\section{Analysis of the Core Genome Among Bacillus Species}

Research on core genomes is important for determining the functional differences and similarities between strains, and provides molecular evidence for phenotypic differences and similarities. Core-genome plot analyses were performed for the four Bacillus genomes (Figure 4). There were 2921 gene families in the final core genome. Among them, 357 (364 CDS), 135 

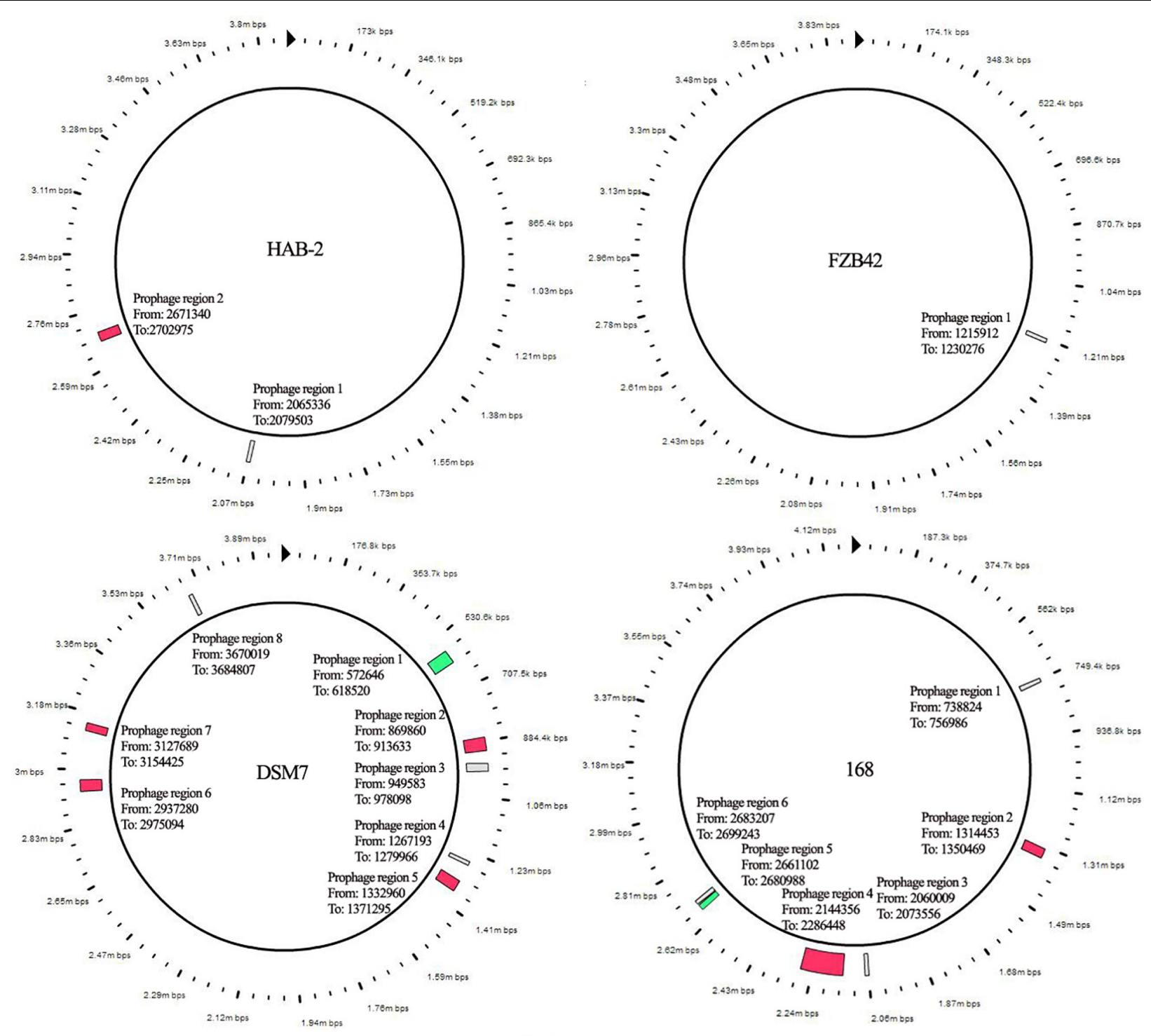

Prophage types

$\square$ intact prophage

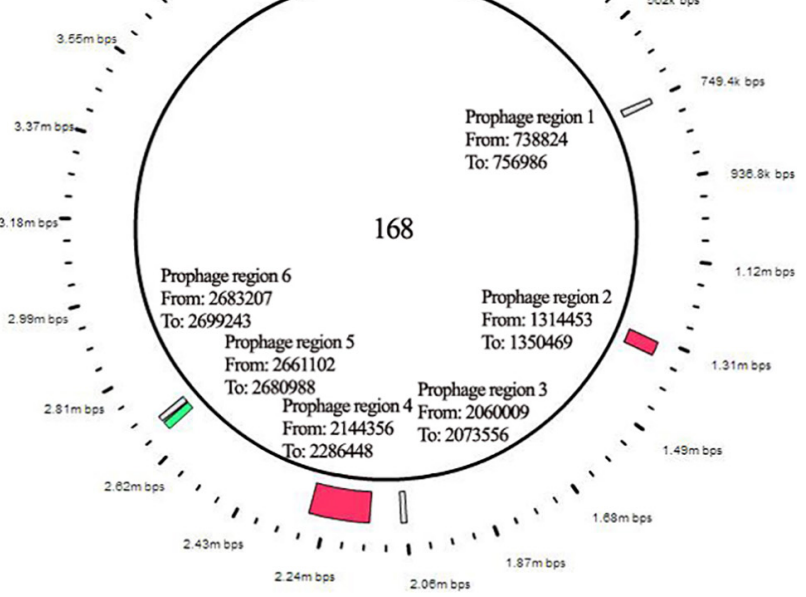

incomplete prophage

questionable prophage

FIGURE 2 | Prophage of B. velezensis HAB-2 and comparison with other Bacillus spp. All prophage regions in different colors code according to completeness, a prediction of whether the region contains an intact or incomplete prophage. If the region's total score is $<70$, it is marked as incomplete (gray); if within 70-90, it is marked as questionable (green); if $>90$, it is marked as intact (red). HAB-2: two prophage regions identified, of which one is intact ( $\operatorname{Pr} 2$, with 46 CDS) and one is incomplete ( $\operatorname{Pr} 1,12$ CDS). Bacillus velezensis FZB42: one prophage region identified, which is incomplete ( $\operatorname{Pr} 1,25$ CDS). Bacillus amyloliquefaciens DSM7: eight prophage regions identified, of which four are intact (Pr2, 46 CDS; $\operatorname{Pr}$ 5, 49 CDS; $\operatorname{Pr}$ 6, 27 CDS; and $\operatorname{Pr}$ 7, 29 CDS), three are incomplete (Pr 3, 24 CDS; $\operatorname{Pr} 4$, 18 CDS; and $\operatorname{Pr} 8,17$ CDS) and one is questionable ( $\operatorname{Pr} 1,63$ CDS). Bacillus subtilis 168: six prophage regions identified, of which two are intact (Pr 2, 49 CDS and $\operatorname{Pr}$ 4, 198 CDS), three are incomplete ( $\operatorname{Pr} 1,20$ CDS; $\operatorname{Pr}$ 3, 13 CDS; and $\operatorname{Pr}$ 6, 23 CDS) and one is questionable ( $\operatorname{Pr} 5,21$ CDS).

(135 CDS), 396 (427 CDS) and 739 gene families (782 CDS) in HAB-2, FZB42, DSM7, and 168 strains were singletons, respectively. Comparison of homology of the gene families showed that HAB-2 and FZB42 had 3,360 gene families in common with an average $87.22 \%$ identity; HAB- 2 and DSM7 had 3,230 gene families in common with average $86.84 \%$ identity; and HAB-2 and 168 had 3,153 gene families in common with average $81.85 \%$ identity. A Venn diagram based on computing of the Bacillus gene families suggested high genetic homogeneity among the four Bacillus strains and close homology among B. velezensis and B. amyloliquefaciens genomes.

\section{Collinearity Analysis of $B$. velezensis HAB-2}

We performed a collinearity analysis to further compare the genomics similarities and differences among the genome of HAB-2 and the genomes of FZB42, DSM7 and 168. The results 


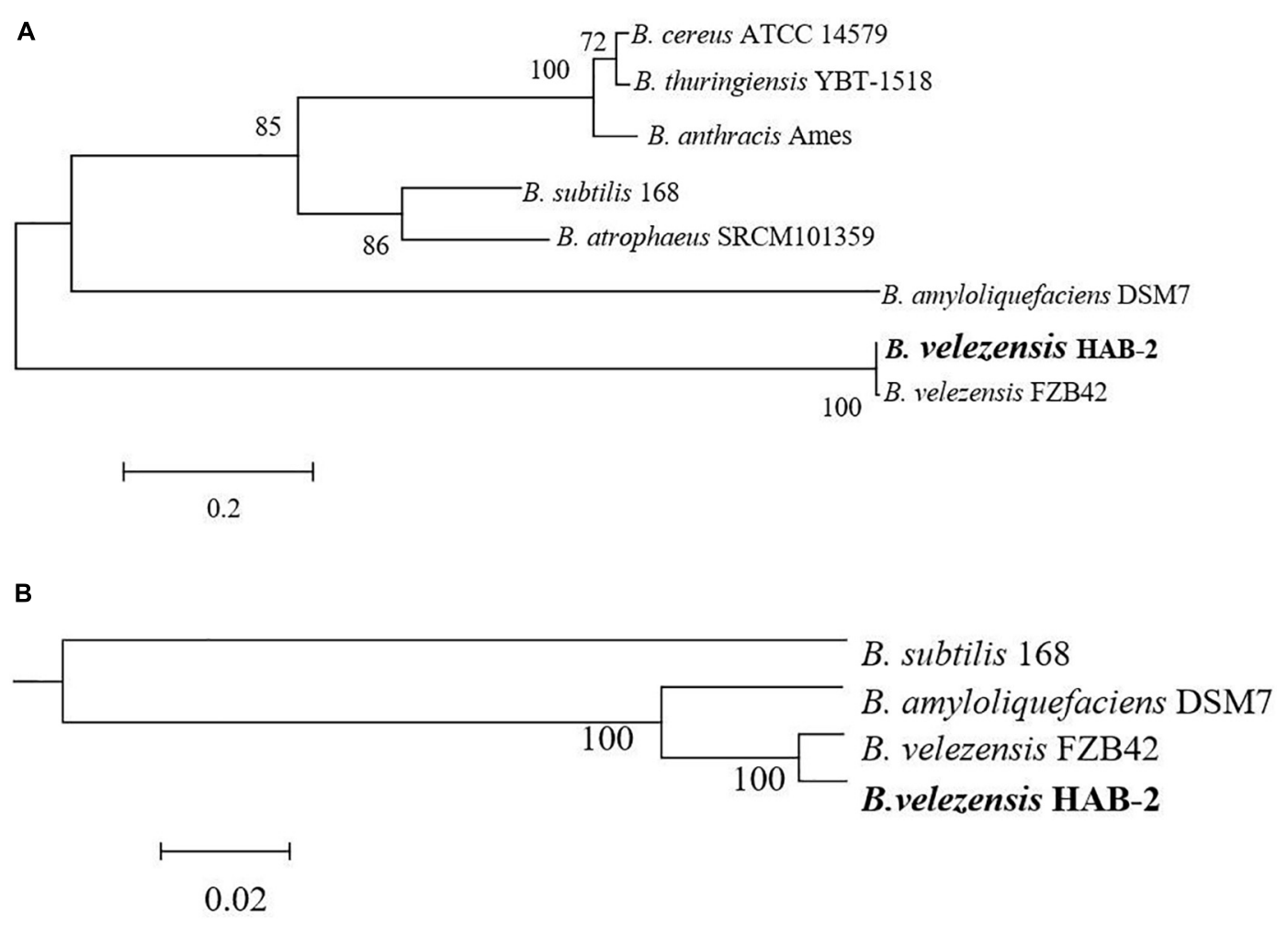

FIGURE 3 | Phylogenetic analysis for B. velezensis HAB-2 and reference Bacillus strains. (A) Phylogenetic tree drawn from the $16 \mathrm{~S}$ rRNA of Bacillus spp. (B) Phylogenetic tree drawn from the core genomes of HAB-2, FZB42, DSM7 and 168. Bootstrap values are indicated in\% of repetitions.

showed that the HAB-2 genome displayed different synteny to those of the other strains (Figure 5). The collinearity of the genome of HAB-2 with those of FZB42, DSM7 and 168 represented approximately $96.14,89.15$, and $22.46 \%$, respectively, of the total length of HAB-2. Of all the sequenced genomes, HAB-2 showed the highest synteny with B. velezensis FZB42, indicating their evolutionary stages were the closest, and their genomes were more related.

\section{Gene Clusters Analysis of B. velezensis HAB-2}

The genomes of Bacillus harbor some important gene clusters involved in the synthesis of secondary metabolites, with antimicrobial, antiviral and nematocidal action. Through use of anti-SMASH genome analysis, 13 clusters of secondary metabolites were identified in the HAB-2 genome (Table 2 and Figure 6), covering $20.08 \%(782.23 \mathrm{~kb})$ of the whole genome and involved in the synthesis of antifungal and antibacterial acting secondary metabolites. This result revealed the potential for biocontrol of plant pathogens in HAB-2. Five gene clusters with a total length of $164.04 \mathrm{~kb}$ were shown to direct unknown compound. There were eight gene clusters related to encoding NRPS and PKS, including Type III PKS cluster and PKS-like cluster directing two unknown compounds. Eight clusters were identified as involved in mersacidin synthesis (GenBank AJ250862.2), bacilysin (GenBank CP000560.1), bacillibactin (GenBank AL009126.3), difficidin
(GenBank AJ634062.2), fengycin (GenBank CP000560.1), bacillaene (GenBank AJ634060.2), macrolactin (GenBank AJ634061.2) and surfactin (GenBank AJ575642.1) (Table 2 and Figure 6). Secondary metabolites clusters were compared to strains FZB42, DSM7 and 168 (Figure 7). Among the 13 gene clusters, two (Clusters 1 and 12) were specific and only existed in HAB-2, two (Clusters 4 and 9) existed in both HAB-2 and FZB42, one (Cluster 11) existed in three strains excluding 168, and the other eight (Clusters 2, 3, 58,10 , and 13) existed in all four strains. Strain HAB-2 had two clusters that were not present in any of the other three strains (Table 2): one (Cluster 1) encoding lanthipeptide was involved in mersacidin synthesis and one (Cluster 12) encoding ladderane was shown to direct an unknown compound. In the same way, we found five clusters (Clusters 5, 6, and 1012) encoding potential novel metabolites with no previously reported description, and four of these were similar to gene clusters in FZB42.

\section{Biosynthesis and Regulation Genes of Secondary Metabolites}

Although several gene clusters were shared by HAB-2, FZB42, DSM7, and 168, the gene structures differed (Figure 8). The fengycin cluster lacked three core genes in DSM7: fenB, fen C, and $f e n D$. In the surfactin cluster, HAB-2 lacked $y c k E$, DSM7 lacked $y c x C$ and $y c x D$, and 168 lacked $y x 01$ (Table 3). Furthermore, the core biosynthetic genes were similar among the four strains. 


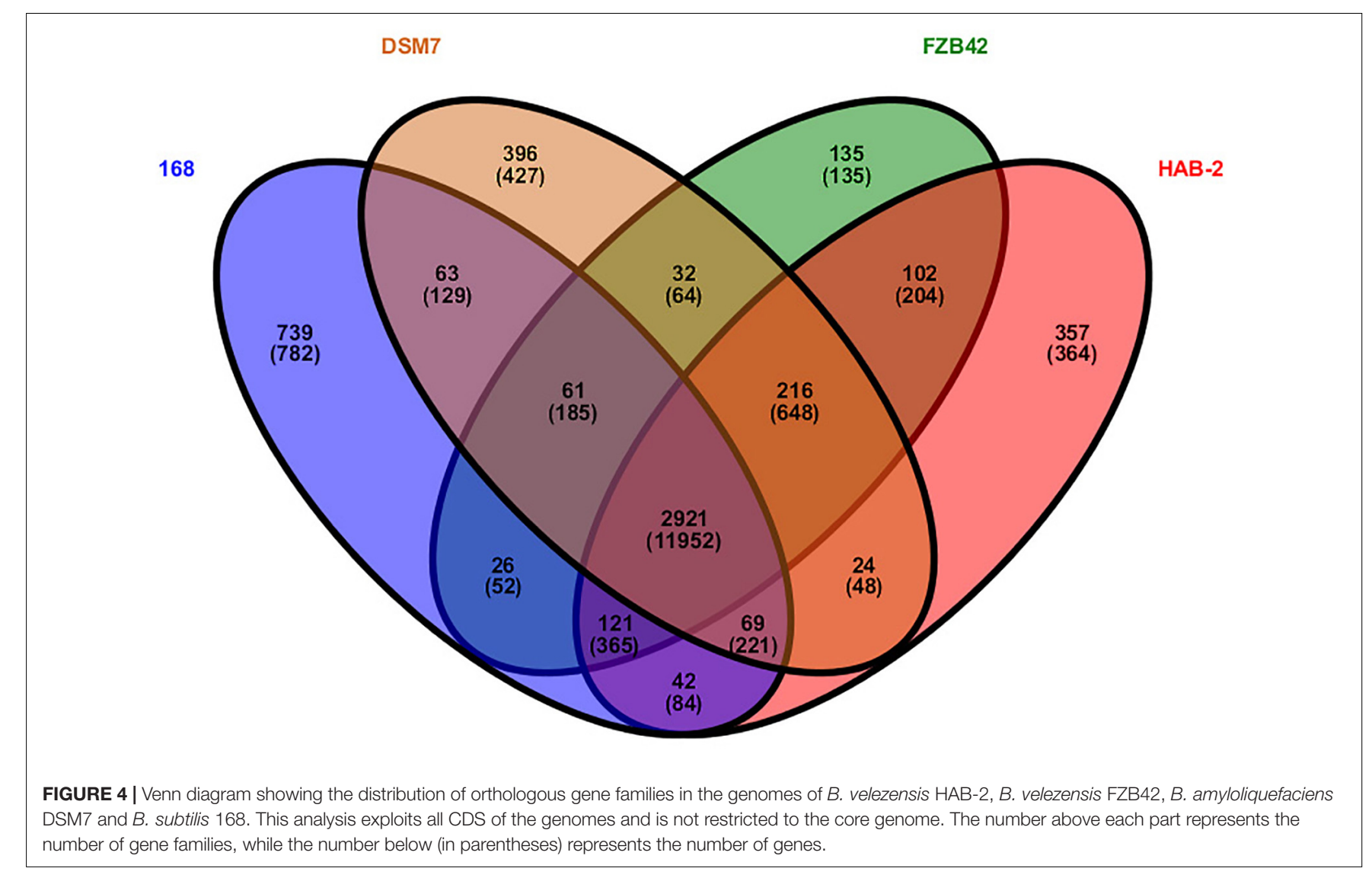

There was a key gene sfp involved in non-ribosomal synthesis, encoding PPTases. A previous study of our research group showed that a $s f p$ homolog $l p a H 2$, which encoded PPTase, was present in HAB-2 (Jin et al., 2017), was 675 bp in size and encoded 224 amino acids. The $\mathrm{Nr}$ annotation information allowed us to obtain the GO function annotation. The GO annotation resulted in three classifications: describing the molecular function (MF), cellular component and biological process (BP) of the gene. Further analysis of the GO annotated genes revealed that lpaH2 appeared only in MF and BP; and lpaH2 appeared five times in $\mathrm{MF}$ and nine times in BP. Bioinformatics analysis of the GO node was performed on these five and nine branches respectively and showed that the HAB-2_2473 gene was consistent with lpaH2 function, was 366 bp in size and encoded 120 amino acids. The NCBI alignment showed that HAB2_2473 had 100\% homology with acpS and encoded PPTase, a member of the PPTase superfamily. The multiple gene functional bioinformatic methods and resources (including Nr, Swiss-Prot, KOG, KEGG, and Pfam) used to analyze the functions of $l p a H 2$ and HAB-2_3473 (acpS) showed that their functions were highly consistent (Table 4).

\section{DISCUSSION}

This study is surefire to identify and classify $B$. velezensis strain HAB-2 based on genomic information using third-generation sequencing technology. The mechanism of biocontrol of HAB-2 was elucidated by analyzing the gene clusters of secondary metabolites. Bacillus species, including B. velezensis, $B$. amyloliquefaciens, and B. subtilis, have been widely researched because of their potential to produce bacteriostatic secondary metabolites (Fan et al., 2018). Bacillus velezensis, isolated from the Vélez River in Málaga in southern Spain, was described in 2005 (Ruiz-García et al., 2005), and B. velezensis was later classified as a heterotypic synonym of B. amyloliquefaciens (Wang et al., 2008). The model B. amyloliquefaciens strain FZB42 was later recognized as synonymous with $B$. velezensis using phylogenomic analysis (Dunlap et al., 2016). The classification of Bacillus spp. has become clearer due to the availability of an increasing number of genome sequences and the former B. amyloliquefaciens was reclassified and divided into B. amyloliquefaciens, B. siamensis, and B. velezensis (Fan et al., 2017). In this study, we compared genome sequences of reference strains B. velezensis FZB42, B. amyloliquefaciens DSM7, and $B$. subtilis 168 , and conducted phylogenomic analysis; the result showed that HAB-2 was $B$. velezensis, which was previously classified as B. amyloliquefaciens.

In this study, we reported a high-quality genome sequence of HAB-2 using third-generation sequencing technology, and made a comparative genome sequence analysis with strains FZB42, DSM7 and 168. The 3.89 Mb genome of HAB-2 encoded 3,820 predicted genes. The four strains were basically identical in regard to whole genome size and the number of genes encoded. The 


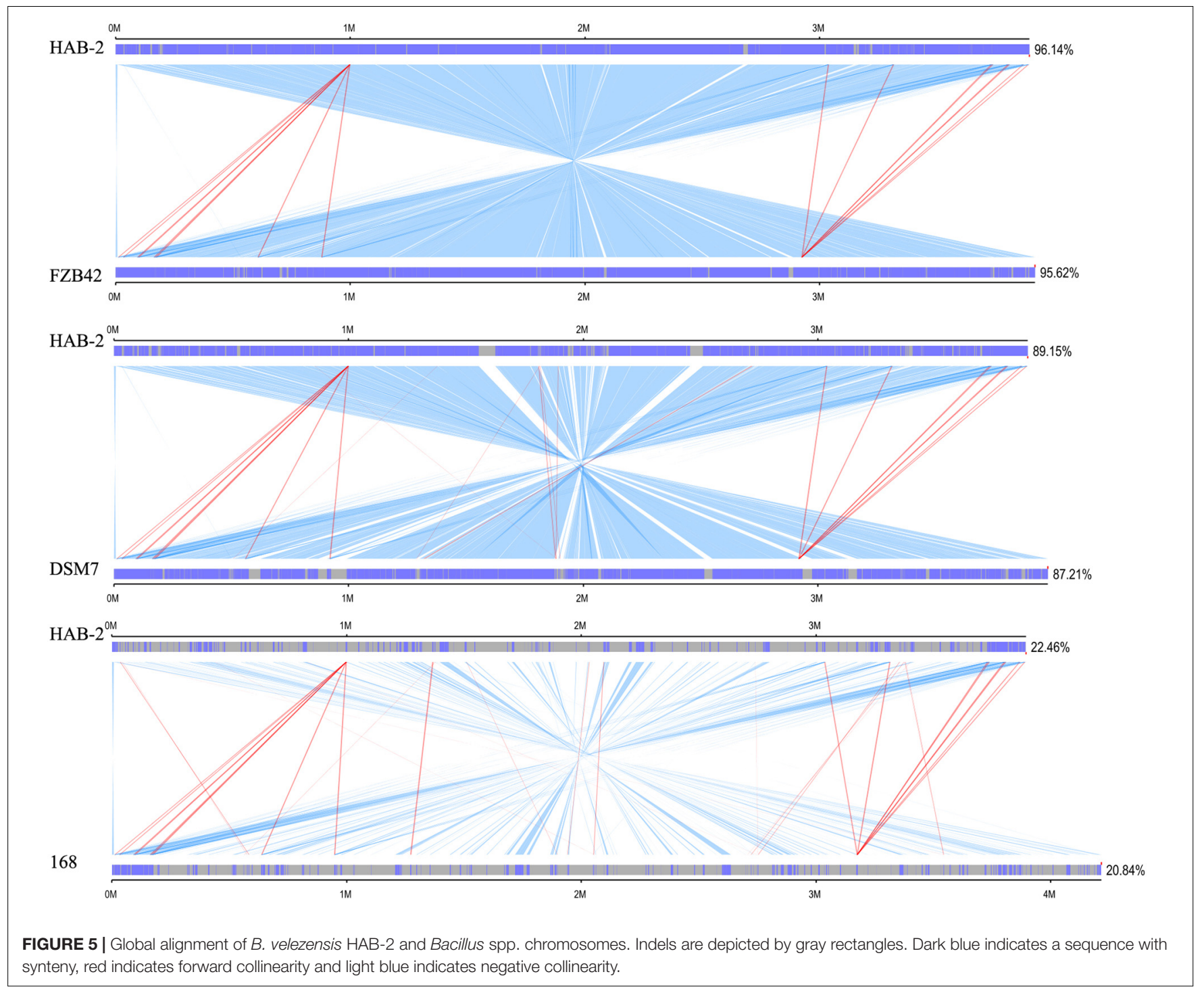

TABLE 2 | Comparative analysis of secondary metabolite clusters of B. velezensis HAB-2 with B. velezensis FZB42, B. amyloliquefaciens DSM7, and B. subtilis 168,

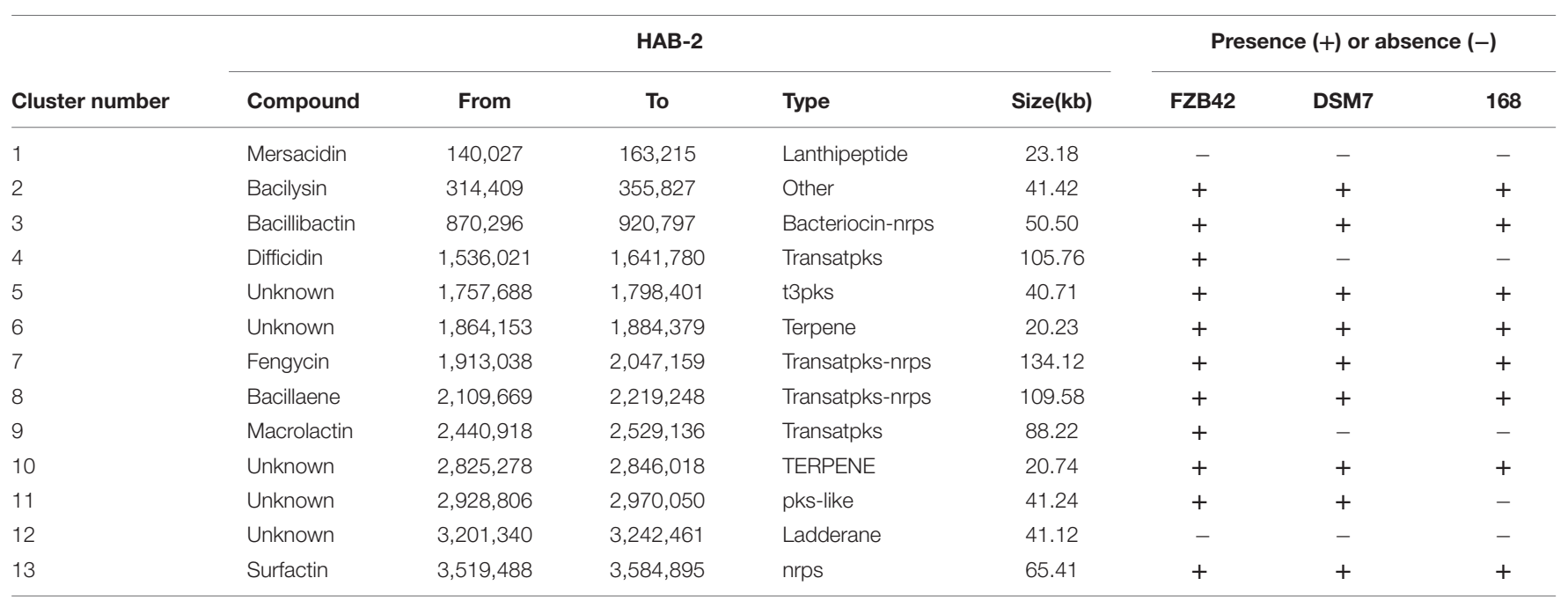

Secondary metabolite antibacterial gene clusters of the four strains were compared and analyzed using anti-SMASH 4.1.0 (Weber et al., 2015). 


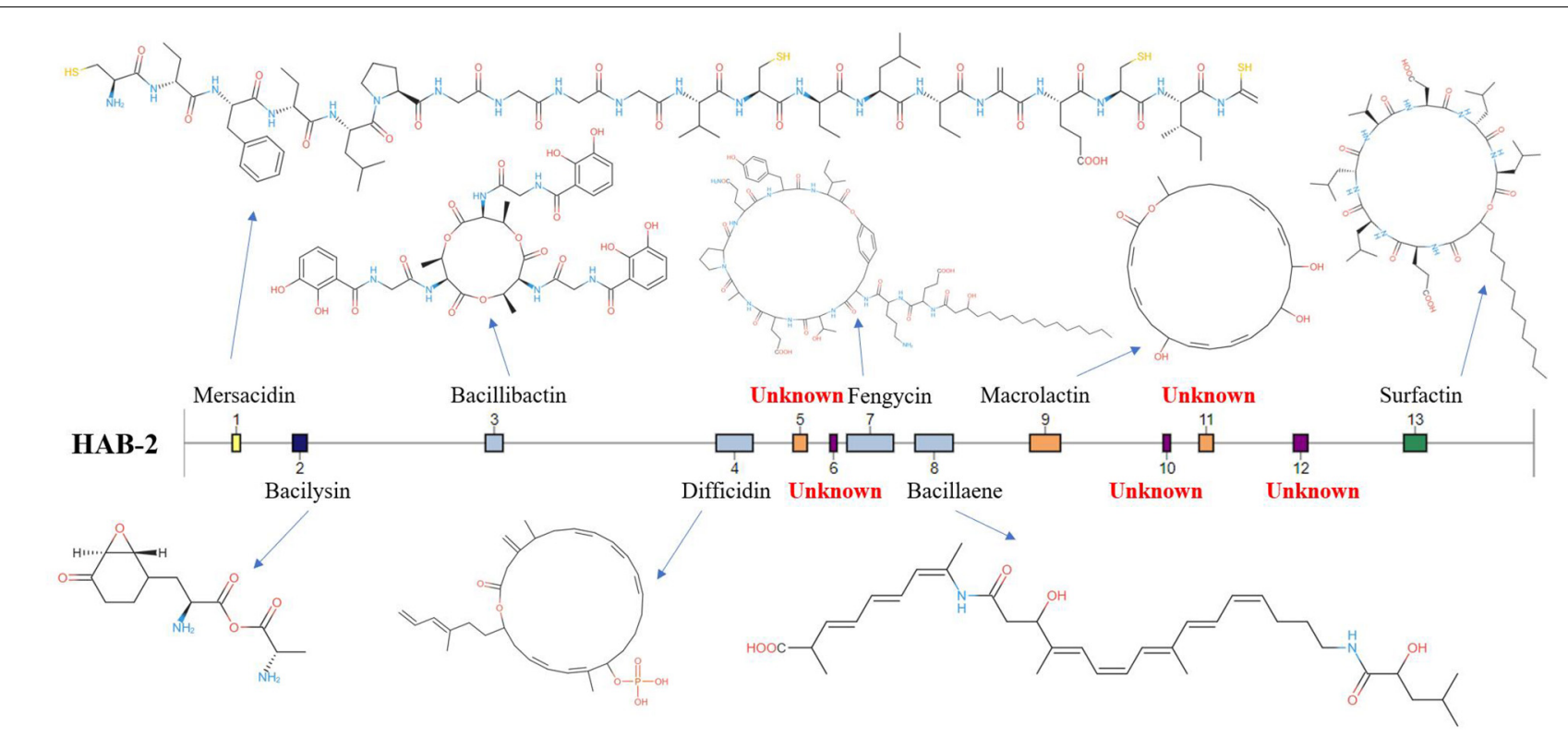

FIGURE 6 | Gene clusters and encoded secondary metabolites identified using the B. velezensis HAB-2 genome.

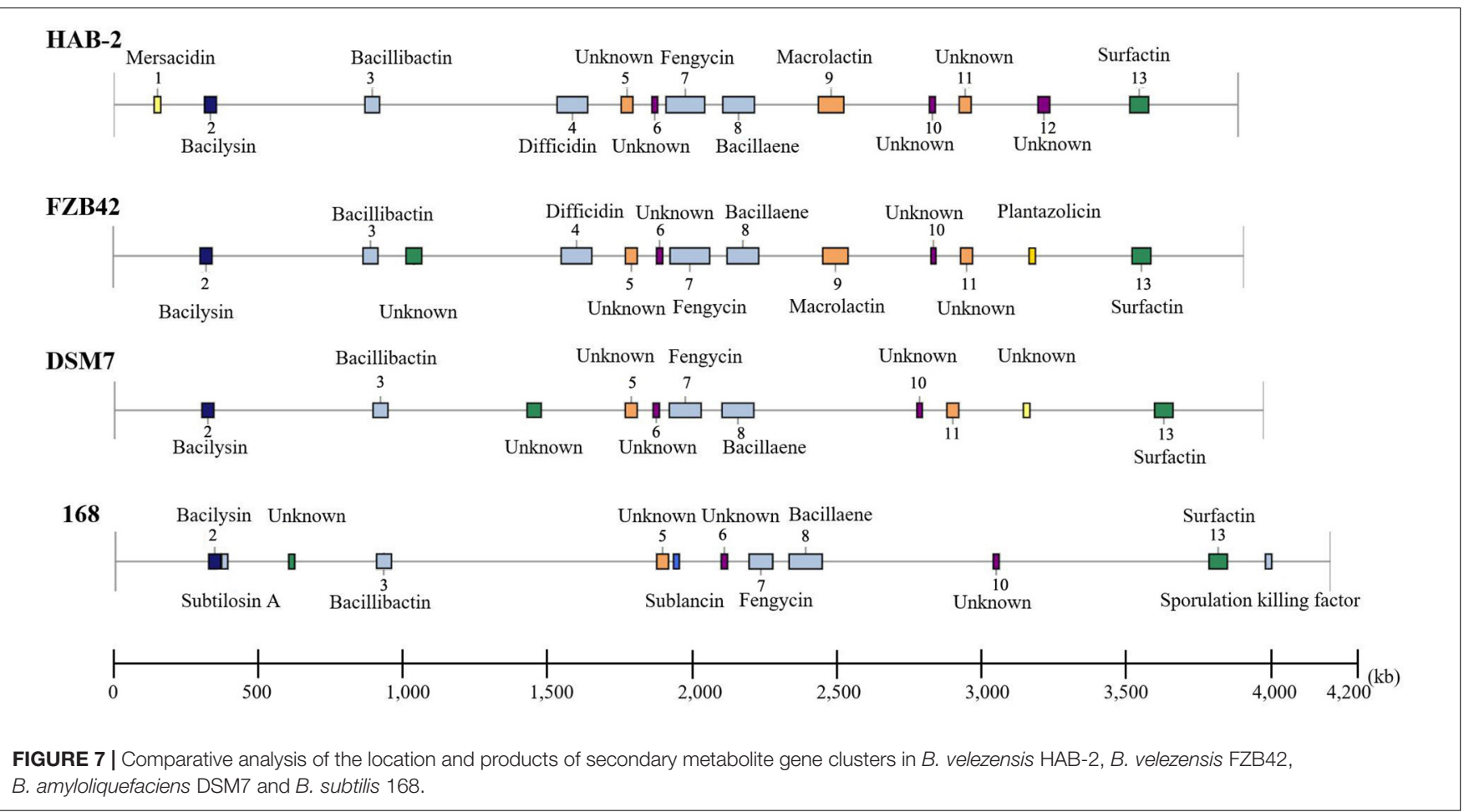

$16 \mathrm{~S}$ rRNA and genome phylogenetic trees showed high similarity with each other and suggested that HAB-2 was most closely related to FZB42 and DSM7. The differences in the genomes of the four strains were the number and size of prophage regions, and the gene clusters encoding secondary metabolites.

Prophages can constitute $3.1-20 \%$ of a bacterium's genome and are major sources of diversification of bacterial genomes; many prophages appear to be defective and are in a state of mutational decay (Casjens, 2005; Touchon et al., 2016). In our study, the prophage regions of the four strains differed and each strain had a defective prophage. This result also confirmed previous studies. Prophages, including defective ones, can contribute important biological properties to their bacterial hosts, such as expressing virulence genes, to sporulate or to differentiate, and serve as active regulatory switches in bacteria by regulating bacterial genes via genome excision (Casjens, 2005; 


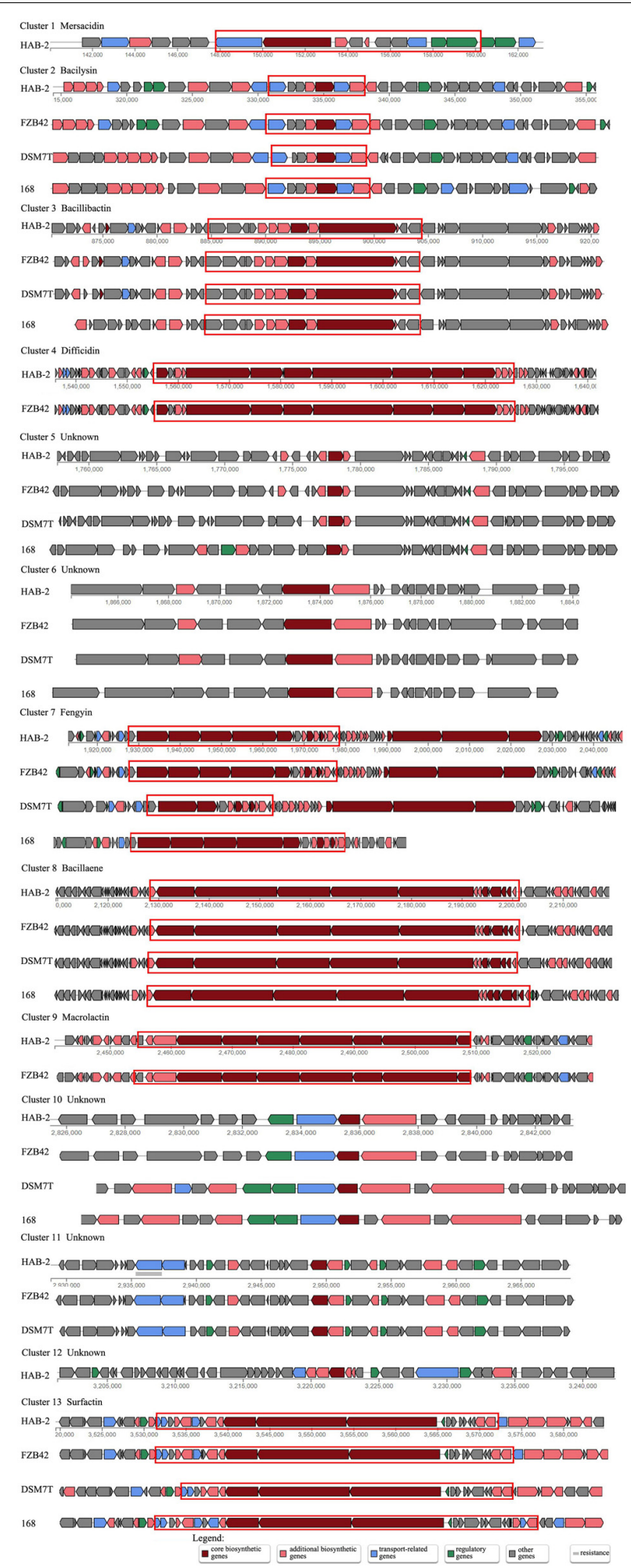

FIGURE 8 | Comparison of biosynthetic gene clusters from $B$. velezensis HAB-2 with B. velezensis FZB42, B. amyloliquefaciens DSM7 and B. subtilis 168. Different genes are filled with different colors: red indicates core biosynthetic genes, pink indicates biosynthetic genes, blue indicates transport-related genes, green indicates regulatory genes and gray indicates other genes. The red circled area is the core biosynthetic part.
Feiner et al., 2015). Prophages may indirectly affect the evolvability of bacteria (Touchon et al., 2016). Wang X. et al. (2010) showed that prophages helped the cell respond to various stresses, and inhibiting key proteins encoded by prophages might be a novel means to combat antibiotic resistance. Pseudomonas aeruginosa produces three types of bacteriocins, and genetically related phages exist for each type - the gene organization of two types of gene clusters suggested that phage tails have been evolutionarily specialized as bacteriocins (Nakayama et al., 2000). Furthermore, prophages have non-homologous modules that can assemble gene clusters (Casjens, 2005; Gilcrease et al., 2005). Thus, the prophage in Bacillus strains may affect the evolutionary, classification and the production of metabolites of the strains.

Based on the $B$. velezensis genomes analysis, more and more secondary metabolite gene clusters have been discovered. B. velezensis $\mathrm{K} 26$ harbors seven gene clusters and it contains a 1-Deoxynojirumycin biosynthetic gene cluster which is a representative iminosugar with alpha-glucosidase inhibition activity (Lee et al., 2020). B. velezensis B-4 harbors 12 gene clusters relating to synthesis of antimicrobial metabolites (Zhu et al., 2020). The HAB-2 genome harbors 13 gene clusters involved in synthesis of antifungal and antibacterial acting secondary metabolites. The number of gene clusters is larger than in other type strains. Notably, HAB-2 has a complete gene cluster, and FZB42 has an incomplete gene cluster, directing mersacidin. Mersacidin is a lanthionine-containing antimicrobial peptide belonging to the family of lantibiotics, and has been identified as a type-B lantibiotic (Bierbaum et al., 1995). It was found in Bacillus sp. Strain HIL Y-85,54728 (Chatterjee et al., 1992). People found that mersacidin could act against methicillinresistant Staphylococcus aureus (Brötz et al., 1997, 1998) and was regarded as a lead member of the type-B lantibiotics. Altena et al. (2000) explored the mersacidin biosynthetic gene cluster and reported the complete sequence of a gene cluster of a typeB lantibiotic. Herzner et al. (2011) transferred genomic DNA of a mersacidin-producing strain to FZB42, which resulted in successful production of mersacidin by FZB42.

The GO function annotation showed that gene function was mainly concentrated in MF and BP. Analysis of gene function revealed genes relevant to cellular process, metabolic process, single-organism process, binding and catalytic activity. As previously mentioned, multidomain enzymes (e.g., PKSs and NRPSs) control the biosynthesis of secondary metabolites (Marahiel et al., 1997; Von Dohren et al., 1997; Metz et al., 2001; Cox, 2007). A same common characteristic of these enzymes is that they require post-translational modification to become active. The apoprotein form (inactive) becomes active (holo form) after the covalent attachment of the $4^{\prime}$-phosphopantetheine moiety, which derives from coenzyme A (Lambalot et al., 1996; García-Estrada et al., 2008). This means that this reaction is catalyzed by PPTase. There is a key gene $s f p$ encoding the PPTase. Borchert et al. (1994) identified that the gsp gene complements a $s f p$ deficiency in a B. subtilis mutant. Huang et al. (1993) and Tsuge et al. (1996) separately discovered $l p a-14$ and $l p a-8$, which regulate production of iturin A, surfactin and plipastatin. Grover et al. (2010) found that B. subtilis strain RP24, which possesses antifungal activity, can produce iturin $A$, surfactin and 
TABLE 3 | Core genes involved with fengycin and surfactin in B. velezensis HAB-2, B. velezensis FZB42, B. amyloliquefaciens DSM7, and B. subtilis 168.

\begin{tabular}{|c|c|c|c|c|c|c|}
\hline \multirow[t]{2}{*}{ Compound } & \multirow[t]{2}{*}{ Gene } & \multicolumn{4}{|c|}{ Presence $(+)$ or absence $(-)$} & \multirow[t]{2}{*}{ Functions or product } \\
\hline & & HAB-2 & FZB42 & DSM7 & 168 & \\
\hline \multirow[t]{6}{*}{ Fengycin } & dacC & + & + & + & + & DacC protein \\
\hline & fenA & + & + & + & + & Fengycin synthetase A, scaffold biosynthesis \\
\hline & fenB & + & + & - & + & Fengycin synthetase B, scaffold biosynthesis \\
\hline & fenc & + & + & - & + & Fengycin synthetase $\mathrm{C}$, scaffold biosynthesis \\
\hline & fenD & + & + & - & + & Fengycin synthetase D, scaffold biosynthesis \\
\hline & fenE & + & + & + & + & Fengycin synthetase E, scaffold biosynthesis \\
\hline \multirow[t]{13}{*}{ Surfactin } & $y \times 01$ & + & + & + & - & Yx01 protein, alcohol dehydrogenase \\
\hline & yckE & - & + & + & + & YckE protein \\
\hline & sifAA & + & + & + & + & Surfactin synthetase A, scaffold biosynthesis \\
\hline & $\operatorname{sif} A B$ & + & + & + & + & Surfactin synthetase B, scaffold biosynthesis \\
\hline & sifAC & + & + & + & + & Surfactin synthetase C, scaffold biosynthesis \\
\hline & sIfAD & + & + & + & + & Surfactin synthetase D, other enzymatic \\
\hline & aat & + & + & + & + & Amino transferase \\
\hline & $y c x C$ & + & + & - & + & Transporter \\
\hline & $y c x D$ & + & + & - & + & Transcriptional regulator containing an aminotransferase domain \\
\hline & sfp & + & + & + & + & Phosphopantetheinyl transferase involved in non-ribosomal synthesis \\
\hline & $y c z E$ & + & + & + & + & Integral membrane protein involved in non-ribosomal synthesis \\
\hline & $y c k l$ & + & + & + & + & Yckl protein \\
\hline & yckJ & + & + & + & + & YckJ protein \\
\hline
\end{tabular}

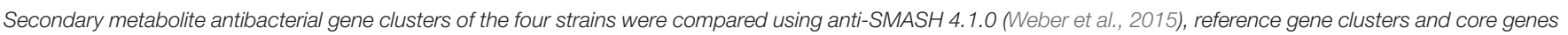
analyzed with MIBiG (Minimum Information about a Biosynthetic Gene cluster) (Kautsar et al., 2020).

TABLE 4 | Comparison of gene function bioinformatics analysis between IpaH2 and acps.

\begin{tabular}{|c|c|c|}
\hline & IpaH2 & acps \\
\hline Size(bp) & 675 & 366 \\
\hline Nr annotation & $\begin{array}{l}4^{\prime} \text {-Phosphopantetheinyl } \\
\text { transferase }\end{array}$ & $\begin{array}{l}4^{\prime} \text {-Phosphopantetheinyl } \\
\text { transferase }\end{array}$ \\
\hline $\begin{array}{l}\text { Swiss-Prot } \\
\text { annotation }\end{array}$ & $\begin{array}{l}4^{\prime} \text {-Phosphopantetheinyl } \\
\text { transferase }\end{array}$ & $\begin{array}{l}\text { Holo-[acyl-carrier-protein] } \\
\text { synthase }\end{array}$ \\
\hline $\begin{array}{l}\text { KOG function } \\
\text { description }\end{array}$ & $\begin{array}{l}\text { Phosphopantetheinyl } \\
\text { transferase }\end{array}$ & $\begin{array}{l}\text { Phosphopantetheinyl } \\
\text { transferase (holo-ACP } \\
\text { synthase) }\end{array}$ \\
\hline KEGG pathway & $\begin{array}{l}\text { Pantothenate and CoA } \\
\text { biosynthesis/etabolism of } \\
\text { cofactors and } \\
\text { vitamins/Metabolism }\end{array}$ & $\begin{array}{l}\text { Pantothenate and CoA } \\
\text { Biosynthesis/Metabolism of } \\
\text { cofactors and } \\
\text { vitamins/Metabolism }\end{array}$ \\
\hline PfamA definition & $\begin{array}{l}4^{\prime} \text {-phosphopantetheinyl } \\
\text { transferase superfamily }\end{array}$ & $\begin{array}{l}\text { 4'-Phosphopantetheinyl } \\
\text { Transferase superfamily }\end{array}$ \\
\hline
\end{tabular}

fengycin and also contains a homolog to $1 p a-14$ found to encode a PPTase. Morikawa et al. (1992) identified the B. pumilus A1 gene $p s f-1$, which regulates surfactin production, and showed that it encoded an active PPTase. Previous study by our research group detected a $s f p$ homolog $l_{p a H}$, which encoded PPTase, in HAB-2 (Jin et al., 2017). The relevant genes encoding PPTases can be screened using a cluster analysis of gene function. In this study, bioinformatics analysis revealed that key gene acpS, which encoded 120 amino acids, encoded the PPTases in HAB-2. This provides significant guidance for subsequent analysis of the antibacterial mechanism of Bacillus spp.

\section{CONCLUSION}

We showed the genetic relationship of B. velezensis $\mathrm{HAB}-2$ with other Bacillus spp. strains through comparative genomic analysis, which is instructive in guiding us to reveal more characteristics of this strain. The differences in prophage regions may provide a new strategy for taxonomic classification and secondary metabolite production of Bacillus. The fact that abundant secondary metabolite gene clusters and unique genes exist in the $B$. velezensis $\mathrm{HAB}-2$ genome illustrates that this strain has potential as a biocontrol bacterium for plant protection in agriculture.

\section{DATA AVAILABILITY STATEMENT}

The datasets presented in this study can be found in online repositories. The names of the repository/repositories and accession number(s) can be found below: https://www.ncbi.nlm. nih.gov/genbank/, MT375545; https://www.ncbi.nlm.nih. gov/genbank/, MT386600; https://www.ncbi.nlm.nih.gov/, CP060085.

\section{AUTHOR CONTRIBUTIONS}

WM and PX designed the experiments and wrote the manuscript. PX, SX, WL, and PJ performed collection and bioinformatics analysis. SX, DW, DY, and YW revised the manuscript. All authors read and approved the final manuscript. 


\section{FUNDING}

This study was supported by the Key Research and Development Program of Hainan Province (No.ZDYF2018240), the National Key R\&D Program of China (No. 2018YFD0201105), the National Natural Science Foundation of China (Grant Nos. 31560495, 31760499 and 31660033), the National Natural Rubber Industry Technical System (No. CARS-34-GW8) and

\section{REFERENCES}

Altena, K., Guder, A., Cramer, C., and Bierbaum, G. (2000). Biosynthesis of the lantibiotic mersacidin: organization of a type b lantibiotic gene cluster. Appl. Environ. Microbiol. 66, 2565-2571. doi: 10.1128/aem.66.6.2565-2571.2000

Ashburner, M., Ball, C. A., Blake, J. A., Botstein, D., Butler, H., Cherry, J. M., et al. (2000). Gene ontology: tool for the unification of biology. Nat. Genet. 25, 25-29. doi: $10.1038 / 75556$

Barbe, V., Cruveiller, S., Kunst, F., Lenoble, P., Meurice, G., Sekowska, A., et al. (2009). From a consortium sequence to a unified sequence: the Bacillus subtilis 168 reference genome a decade later. Microbiology 155, 1758-1775. doi: 10. 1099/mic.0.027839-0

Beld, J., Sonnenschein, E. C., Vickery, C. R., Noel, J. P., and Burkart, M. D. (2014). The phosphopantetheinyl transferases: catalysis of a posttranslational modification crucial for life. Nat. Prod. Rep. 31, 61-108. doi: 10.1039/ c3np70054b

Besemer, J., Lomsadze, A., and Borodovsky, M. (2001). GeneMarkS: a self-training method for prediction of gene starts in microbial genomes. Implications for finding sequence motifs in regulatory regions. Nucleic Acids Res. 29, 2607-2618. doi: 10.1093/nar/29.12.2607

Bierbaum, G., Brotz, H., Koller, K. P., and Sahl, H. G. (1995). Cloning, sequencing and production of the lantibiotic mersacidin. FEMS Microbiol. Lett. 127, 121126. doi: 10.1016/0378-1097(95)00048-A

Blom, J., Albaum, S., Doppmeier, D., Pühler, A., Vorhölter, F., Zakrzewski, M. et al. (2009). EDGAR: a software framework for the comparative analysis of prokaryotic genomes. BMC Bioinformatics 10:154. doi: 10.1186/1471-2105 10-154

Borchert, S., Stachelhaus, T., and Marahiel, M. A. (1994). Induction of surfactin production in Bacillus subtilis by $g s p$, a gene located upstream of the gramicidin S operon in Bacillus brevis. J. Bacteriol. 176, 2458-2462. doi: 10.1128/jb.176.8. 2458-2462.1994

Brötz, H., Bierbaum, G., Leopold, K., Reynolds, P. E., and Sahl, H. G. (1998). The lantibiotic mersacidin inhibits peptidoglycan synthesis by targeting lipid II. Antimicrob. Agents Chemother. 42, 154-160. doi: 10.1128/aac.42.1.154

Brötz, H., Bierbaum, G., Reynolds, P. E., and Sahl, H. G. (1997). The lantibiotic mersacidin inhibits peptidoglycan biosynthesis at the level of trans glycosylation. Eur. J. Biochem. 246, 193-199. doi: 10.1111/j.1432-1033.1997. t01-1-00193.X

Casjens, S. R. (2005). Comparative genomics, and evolution of the tailedbacteriophages. Curr. Opin. Microbiol. 8, 451-458. doi: 10.1046/j.1365-2958. 2003.03580.X

Chatterjee, S., Chatterjee, S., Lad, S. J., Phansalkar, M. S., Rupp, R. H., Ganguli, B. N., et al. (1992). Mersacidin, a new antibiotic from Bacillus: fermentation, isolation, purification and chemical characterization. J. Antibiot. 45, 832-838. doi: 10.7164/antibiotics.45.832

Chen, L. H., Zheng, D. D., Liu, B., Yang, J., and Jin, Q. (2016). VFDB 2016: hierarchical and refined dataset for big data analysis-10 years on. Nucleic Acids Res. 44, D694-D697. doi: 10.1093/nar/gkv1239

Chen, X. H., Koumoutsi, A., Scholz, R., Eisenreich, A., Schneider, K., Heinemeyer, I., et al. (2007). Comparative analysis of the complete genome sequence of the plantgrowth-promoting bacterium Bacillus amyloliquefaciens FZB42. Nat. Biotechnol. 25, 1007-1014. doi: 10.1002/9781118297674.ch83

Chen, X. H., Koumoutsi, A., Scholz, R., Schneider, K., Vater, J., Süssmuth, R., et al. (2008). Genome analysis of Bacillus amyloliquefaciens FZB42 reveals its potential for biocontrol of plant pathogens. J. Biotechnol. 140, 27-37. doi: 10. 1016/j.jbiotec.2008.10.011
Hainan Major Research Fund of Science and Technology (No. ZDKJ201817).

\section{ACKNOWLEDGMENTS}

We gratefully acknowledge Prof. Xiangfeng Wang and Dr. Jianan Wang for useful discussions about this article.

Chin, C. S., Alexander, D. H., Marks, P., Klammer, A. A., Drake, J., Heiner, C. et al. (2013). Nonhybrid, finished microbial genome assemblies from long-read SMRT sequencing data. Nat. Methods 10, 563-569. doi: 10.1038/nmeth.2474

Coenye, T., and Vandamme, P. (2010). Intragenomic heterogeneity between multiple $16 \mathrm{~S}$ ribosomal RNA operons in sequenced bacterial genomes. FEMS Microbiol. Lett. 228, 45-49. doi: 10.1016/S0378-1097(03)00717-1

Compant, S., Duffy, B., Nowak, J., Clement, C., and Barka, E. A. (2005). Use of plant growth-promoting bacteria for biocontrol of plant diseases: principles, mechanism sofaction, and future prospects. Appl. Environ. Microbiol. 71, 49514959. doi: 10.1128/AEM.71.9.4951-4959.2005

Conesa, A., Gotz, S., Garcia-Gomez, J. M., Terol, J., Talón, M., and Robles, M. (2005). Blast2GO: a universal tool for annotation, visualization and analysis in functional genomics research. Bioinformatics 21, 3674-3676. doi: 10.1093/ bioinformatics/bti610

Cox, R. J. (2007). Polyketides. Proteins and genes in fungi: programmed nanomachines begin to reveal their secrets. Cheminform 5, 2010-2026. doi: 10.1039/ b704420h

Darling, A. E., Mau, B., and Perna, N. T. (2010). progressive Mauve: multiple genome alignment with gene gain, loss and rearrangement. PLoS One 5:e11147. doi: 10.1371/journal.pone.0011147

Dunlap, C., Kim, S. J., Kwon, S. W., and Rooney, A. P. (2016). Bacillus velezensis is not a later heterotypic synonym of Bacillus amyloliquefaciens, Bacillus methylotrophicus, Bacillus amyloliquefaciens subsp. plantarum and 'Bacillus oryzicola' are later heterotypic synonyms of Bacillus velezensis based on phylogenomics. Int. J. Syst. Evol. Microbiol. 66, 1212-1217. doi: 10.1099/ijsem. 0.000858

Fan, B., Blom, J., Klenk, H. P., and Rainer, B. (2017). Bacillus amyloliquefaciens, Bacillus velezensis, and Bacillus siamensis form an "operational group B. amyloliquefaciens" within the B. subtilis species complex. Front. Microbiol. 8:22. doi: $10.3389 /$ fmicb. 2017.00022

Fan, B., Wang, C., Song, X., Ding, X. L., Wu, L. M., Wu, H. J., et al. (2018). Bacillus velezensis FZB42 in 2018: the Gram-positive model strain for plant growth promotion and biocontrol. Front. Microbiol. 9:2491. doi: 10.3389/fmicb.2018. 0249

Feiner, R., Argov, T., Rabinovich, L., Sigal, N., Borovok, I., and Herskovits, A. A (2015). A new perspective on lysogeny: prophages as active regulatory switches of bacteria. Nat. Rev. Microbiol. 13, 641-650. doi: 10.1038/nrmicro3527

Finn, R. D., Bateman, A., Clements, J., Coggill, P., Eberhardt, R. Y., Eddy, S. R., et al. (2014). Pfam: the protein families database. Nucleic Acids Res. 42, D222-D230. doi: $10.1093 /$ nar/gkt1223

Galperin, M. Y., Makarova, K. S., Wolf, Y. I., and Eugene, V. K. (2015). Expanded microbial genome coverage and improved protein family annotation in the COG database. Nucleic Acids Res. 43, D261-D269. doi: 10.1093/nar/ gku1223

García-Estrada, C., Ricardo, V. U., Velasco-Conde, T., Ramiro, P. G., Fernando, T., Inmaculada, V., et al. (2008). Post-translational enzyme modification by the phosphopantetheinyl transferase is required for lysine and penicillin biosynthesis but not for roquefortine or fatty acid formation in Penicillium chrysogenum. Biochem. J. 415, 317-324. doi: 10.1042/BJ20080369

Gardner, P. P., Daub, J., Tate, J. G., Nawrocki, E. P., Kolbe, D. L., Lindgreen, S., et al. (2009). Rfam: updates to the RNA families database. Nucleic Acids Res. 37, D136-D140. doi: 10.1093/nar/gkn766

Gilcrease, E. B., Winn-Stapley, D. A., Hewitt, F. C., Joss, L., and Casjens, S. R. (2005). Nucleotide sequence of the head assembly gene cluster of bacteriophage L and decoration protein characterization. J. Bacteriol. 187, 2050-2057. doi: 10.1128/JB.187.6.2050-2057.2005 
Grover, M., Nain, L., Singh, S. B., and Saxena, A. K. (2010). Molecular and biochemical approaches for characterization of antifungal trait of a potent biocontrol agent Bacillus subtilis RP24. Curr. Microbiol. 60, 99-106. doi: 10. 1007/s00284-009-9508-6

Herzner, A. M., Dischinger, J., Szekat, C., Josten, M., Schmitz, S., Yakéléba, A., et al. (2011). Expression of the lantibiotic mersacidin in Bacillus amyloliquefaciens FZB42. PLoS One 6:e22389. doi: 10.1371/journal.pone.0022389

Huang, C. C., Ano, T., and Shoda, M. J. (1993). Nucleotide sequence and characteristics of the gene, lpa-14, responsible for biosynthesis of the lipopeptide antibiotics iturin A and surfactin from Bacillus subtilis RB14. J. Ferment. Bioeng. 76, 445-450. doi: 10.1016/0922-338x(93)90238-4

Jin, P. F., Wang, H. N., Liu, W. B., Fan, Y. M., and Miao, W. G. (2018). A new cyclic lipopeptide isolated from Bacillus amyloliquefaciens HAB-2 and safety evaluation. Pestic. Biochem. Physiol. 147, 40-45. doi: 10.1016/j.pestbp.2017. 08.015

Jin, P. F., Wang, H. N., Liu, W. B., and Miao, W. G. (2017). Characterization of lpaH2 gene corresponding to lipopeptide synthesis in Bacillus amyloliquefaciens HAB-2. BMC Microbiol. 17:227. doi: 10.1186/s12866-017-1134-z

Jones, P., Binns, D., Chang, H. Y., Fraser, M., Li, W. Z., McAnulla, C., et al. (2014). InterProScan 5: genome-scale protein function classification. Bioinformatics 30, 1236-1240. doi: 10.1093/bioinformatics/btu031

Kanehisa, M., Sato, Y., Kawashima, M., Furumichi, M., and Tanabe, M. (2016). KEGG as a reference resource for gene and protein annotation. Nucleic Acids Res. 44, D457-D462. doi: 10.1093/nar/gkv1070

Kautsar, S. A., Blin, K., Shaw, S., Navarro-Muñoz, J. C., Terlouw, B. R., Hooft, J. J. J., et al. (2020). Mibig 2.0: a repository for biosynthetic gene clusters of known function. Nucleic Acids Res. 48, D454-D458. doi: 10.1093/nar/gkz882

Koren, S., Schatz, M. C., Walenz, P. B., Jeffrey, M., Jason, T. H., Ganeshkumar, G., et al. (2012). Hybrid error correction and de novo assembly of single-molecule sequencing reads. Nat. Biotechnol. 30, 693-700. doi: 10.1038/nbt.2280

Koumoutsi, A., Chen, X. H., Henne, A., Liesegang, H., Hitzeroth, G., Franke, P., et al. (2004). Structural and functional characterization of gene clusters directing nonribosomal synthesis of bioactive cyclic lipopeptides in Bacillus amyloliquefaciens strain FZB42. J. Bacteriol. 186, 1084-1096. doi: 10.1128/JB 186.4.1084-1096.2004

Kurtz, S., Phillippy, A., Delcher, A. L., Michael, S., Martin, S., Corina, A., et al. (2004). Versatile and open software for comparing large genomes. Genome Biol. 5:R12. doi: 10.1186/gb-2004-5-2-r12

Lagesen, K., Hallin, P., Rodland, E., Staerfeldt, A., Rognes, T. H. H., and Ussery, D. W. (2007). RNAmmer: consistent and rapid annotation of ribosomal RNA genes. Nucleic Acids Res. 35, 3100-3108. doi: 10.1093/nar/gkm160

Lambalot, R. H., Gehring, A. M., Flugel, R. S., Zuber, P., and Walsh, C. T. (1996) A new enzyme superfamily-the phosphopantetheinyl transferases. Chem. Biol. 3, 923-936. doi: 10.1016/S1074-5521(96)90181-7

Lee, H., Jung, D. H., Seo, D. H., Chung, W. H., and Seo, M. J. (2020). Genome analysis of 1-deoxynojirimycin (1-DNJ)-producing Bacillus velezensis K26 and distribution of Bacillus sp. harboring a 1-DNJ biosynthetic gene cluster. Genomics doi: 10.1016/j.ygeno.2020.09.061 [Epub ahead of print].

Levasseur, A., Drula, E., Lombard, V., Coutinho, P. M., and Henrissat, B. (2013). Expansion of the enzymatic repertoire of the CAZy database to integrate auxiliary redox enzymes. Biotechnol. Biofuels 6:41. doi: 10.1186/17546834-6-41

Liu, B., and Pop, M. (2009). ARDB-antibiotic resistance genes database. Nucleic Acids Res. 37, D443-D447. doi: 10.1093/nar/gkn656

Lowe, T. M., and Eddy, S. R. (1997). tRNAscan-SE: a program for improved detection of transfer RNA genes in genomic sequence. Nucleic Acids Res. 25, 955-964. doi: 10.1093/nar/25.5.955

Makarova, K., Wolf, Y., and Koonin, E. (2015). Archaeal clusters of orthologous genes (arCOGs): an update and application for analysis of shared features between Thermococcales, Methanococcales, and Methanobacteriales. Life 5, 818-840, doi: 10.3390/life5010818

Marahiel, M. A., Stachelhaus, T., and Mootz, H. D. (1997). Modular peptide synthetases involved in nonribosomal peptide synthesis. Chem. Rev. 97, 26512674. doi: $10.1021 / \mathrm{cr} 960029 \mathrm{e}$

Mariappan, A., Makarewicz, O., Chen, X. H., and Borriss, R. (2012). Twocomponent response regulator DegU controls the expression of bacilysin in plant-growth-promoting bacterium Bacillus amyloliquefaciens FZB42. J. Biotechnol. 22, 114-125. doi: 10.1159/000338804
Metz, J. G., Roessler, P., Facciotti, D., Levering, C., Dittrich, F., Lassner, M., et al. (2001). Production of polyunsaturated fatty acids by polyketide synthases in both prokaryotes and eukaryotes. Science 293, 290-293. doi: 10.1126/science. 1059593

Morikawa, M., Ito, M., and Imanaka, T. (1992). Isolation of a new surfactin producer Bacillus pumilus, A-1, and cloning and nucleotide sequence of the regulator gene, psf-1. J. Ferment. Bioeng. 74, 255-261. doi: 10.1016/0922338X(92)90055-Y

Myers, E. W., Sutton, G. G., Delcher, A. L., Dew, I. M., Fasulo, D. P., Flanigan, M. J. et al. (2000). A whole-genome assembly of Drosophila. Science 287, 2196-2204. doi: $10.1126 /$ science.287.5461.2196

Nakano, M. M., Corbell, N., Besson, J., and Zuber, P. (1992). Isolation and characterization of $s f p$ : a gene that functions in the production of the lipopeptide biosurfactant, surfactin, in Bacillus subtilis. Mol. Genet. Genomics 232, 313-321. doi: $10.1007 /$ bf00280011

Nakano, M. M., Marahiel, M. A., and Zuber, P. (1990). Identification of a genetic locus required for biosynthesis of the lipopeptide antibiotic surfactin in Bacillus subtilis. Genet. Biotechnol. Bacilli 170, 397-405. doi: 10.1016/B9780-12-274162-3.50047-5

Nakayama, K., Takashima, K., Ishihara, H. T., Shinomiya, M., Kageyama, S. K., et al. (2000). The R-type pyocin of Pseudomonas aeruginosa is related to P2 phage, and the F-type is related to lambda phage. Mol. Microbiol. 38, 213-231. doi: 10.1046/j.1365-2958.2000.02135.x

Nandi, T., Ong, C., Singh, A. P., Justin, B., Timothy, A., Mitali, S. T., et al. (2010). A genomic survey of positive selection in Burkholderia pseudomallei provide sinsights into the evolution of accidental virulence. PLoS Pathog. 6:e1000845. doi: 10.1371/journal.ppat.1000845

Qiao, J. Q., Wu, H. J., Huo, R., Gao, X. W., and Borriss, R. (2014). Stimulation and biocontrol by Bacillus amyloliquefaciens subsp. plantarum FZB42 engineered for improved action. Chem. Biol. Technol. Agric. 1:12. doi: 10.1186/s40538-0140012-2

Rückert, C., Blom, J., Chen, X. H., Oleg, R., and Rainer, B. (2011). Genome sequence of $B$. amyloliquefaciens type strain DSM7(T) reveals differences to plant-associated B. amyloliquefaciens FZB42. J. Biotechnol. 155, 78-85. doi: 10.1016/j.jbiotec.2011.01.006

Ruiz-García, C., Béjar, V., Martínez-Checa, F., Llamas, I., and Quesada, E. (2005). Bacillus velezensis sp. nov., a surfactant-producing bacterium isolated from the river Vélez in Málaga, Southern Spain. Int. J. Syst. Evol. Microbiol. 55, 191-195. doi: 10.1099/ijs.0.63310-0

Schäfer, T., and Adams, T. (2015). "The importance of microbiology in sustainable agriculture," in Principles of Plant-Microbe Interactions. Microbes for Sustainable Agriculture, ed. B. Lugtenberg (Berlin: Springer), 5-6. doi: 10.1007/978-3-31908575-3

Schneider, K., Chen, X. H., Vater, J., Franke, P., Nicholson, G., Borriss, R., et al. (2007). Macrolactin is the polyketide biosynthesis product of the pks2 cluster of Bacillus amyloliquefaciens FZB42. J. Nat. Prod. 70, 1417-1423. doi: 10.1021/ np070070k

Tamura, K., Dudley, J., Nei, M., and Kumar, S. (2007). MEGA4: molecular evolutionary genetics analysis (MEGA) software version 4.0. Mol. Biol. Evol. 24, 1596-1599. doi: 10.1093/molbev/msm092

Tarailo-Graovac, M., and Chen, N. S. (2009). Using repeat masker to identify repetitive elements in genomic sequences. Curr. Protoc. Bioinformatics 5 4.10.1-4.10.14. doi: 10.1002/0471250953.bi0410s05

Touchon, M., Bernheim, A., and Rocha, E. P. (2016). Genetic and life-history traits associated with the distribution of prophages in bacteria. ISME J. 10, 2744-2754. doi: 10.1038/ismej.2016.47

Tsuge, K., Ano, T., and Shoda, M. (1996). Isolation of a gene essential for biosynthesis of the lipopeptide antibiotics plipastatin B1 and surfactin in Bacillus subtilis YB8. Arch. Microbiol. 165, 243-251. doi: 10.1007/ s002030050322

UniProt Consortium (2015). UniProt: a hub for protein information. Nucleic Acids Res. 43, D204-D212. doi: 10.1093/nar/gku989

Von Dohren, H., Keller, U., Vater, J., and Rainer, Z. (1997). Multifunctional peptide synthetases. Chem. Rev. 97, 2675-2706. doi: 10.1021/cr9600262

Wang, D., Zhang, Y., Zhang, Z., Zhu, J., and Yu, J. (2010). KaKs_Calculator 2.0: a toolkit incorporating gamma series methods and sliding window strategies. Genomics Proteomics Bioinformatics 8, 77-80. doi: 10.1016/S1672-0229(10) 60008-3 
Wang, L. T., Lee, F. L., Tai, C. J., and Kuo, H. P. (2008). Bacillus velezensis is a later heterotypic synonym of Bacillus amyloliquefaciens. Int. J. Syst. Evol. Microbiol. 58, 671-675. doi: 10.1016/j.diamond.2007.11.010

Wang, X., Kim, Y., Ma, Q., Hong, S. H., Pokusaeva, K., Sturino, J., et al. (2010). Cryptic prophages help bacteria cope with adverse environments. Nat. Commun. 1:147. doi: 10.1038/ncomms1146

Weber, T., Blin, K., Duddela, S., Daniel, K., Hyun, U. K., Robert, B., et al. (2015). antiSMASH 3.0-a comprehensive resource for the genome mining of biosynthetic gene clusters. Nucleic Acids Res. 43, 237-243. doi: 10.1093/nar/ gkv437

Winnenburg, R., Baldwin, T. K., Urban, M., Rawlings, C., Köhler, J., HammondKosack, K. E., et al. (2006). PHI-base: a new database for pathogen host interactions. Nucleic Acids Res. 34, D459-D464. doi: 10.1093/nar/gkj047

Zhou, Y., Liang, Y., Lynch, K. H., Dennis, J. J., and Wishart, D. S. (2011). PHAST: a fast phage search tool. Nucleic Acids Res. 39(Suppl. 2), W347-W352. doi: $10.1093 / \mathrm{nar} / \mathrm{gkr} 485$
Zhu, Z. Y., Peng, Q., Man, Y. L., Li, Z. R., Zhou, X. M., Bai, L. Y., et al. (2020). Analysis of the antifungal properties of Bacillus velezensis B-4 through a bioassay and complete-genome sequencing. Front. Genet. 7:703. doi: 10.3389/ fgene.2020.00703

Conflict of Interest: The authors declare that the research was conducted in the absence of any commercial or financial relationships that could be construed as a potential conflict of interest.

Copyright (C) $2020 \mathrm{Xu}$, Xie, Liu, Jin, Wei, Yaseen, Wang and Miao. This is an openaccess article distributed under the terms of the Creative Commons Attribution License (CC BY). The use, distribution or reproduction in other forums is permitted, provided the original author(s) and the copyright owner(s) are credited and that the original publication in this journal is cited, in accordance with accepted academic practice. No use, distribution or reproduction is permitted which does not comply with these terms. 